\title{
Развитие концептуальных основ налогового менеджмента
}

\author{
Е. И. Костюкова ${ }^{1}$ В. С. Германова \\ 1,2,3 Ставропольский государственный аграрный университет, пер. Зоотехнический, 12, \\ 355017, Ставрополь, Российская Федерация
}

Для цитирования: Костюкова Е. И., Германова В. С., Фролов А. В. Развитие концептуальных основ налогового менеджмента // Вестник Воронежского государственного университета. Серия: Экономика и управление. 2020. № 2. С. 66-74. DOI: 10.17308/econ.2020.2/2902

Предмет. Задачей стратегии устойчивого развития Российской Федерации является обеспечение стабильных показателей экономического роста, а также решение социально-экономических, производственно-технологических и природно-экологических проблем на основе оптимального использования инновационного и научно-технического потенциалов, обновления техники и технологий, расширения рынков сбыта. При этом результативность самого инновационного процесса во многом будет зависеть от готовности хозяйствующих субъектов внедрять и использовать современные наукоемкие технологии, которые могут проявиться в налоговой политике.

Цели. Обоснование и уточнение фактов о том, что налоговый менеджмент является составной частью всей налоговой политики и представляет собой систему принципов и методов в области разработки и реализации управленческих решений, выбора налоговой системы, расчета налоговых платежей, а также постоянного контроля за их осуществлением.

Методология. Инструментарно-методический аппарат исследования основан на использовании общенаучных и специальных методов, включая абстрактно-логический, монографический, расчетно-конструктивный, методы анализа рисков, экономико-математическое моделирование, графический, методы многомерного статистического анализа, контент-анализ.

Результаты. Налоги всегда являлись важнейшим инструментом государственного регулирования, реализующим главные задачи государства. Налогообложение порождает налоговые отношения, которые необходимо правильно регулировать посредством применения налогового законодательства. Такое взаимодействие сподвигает экономические субъекты осуществлять управление своими налоговыми платежами, поэтому они начинают применять в своей деятельности самые разнообразные методики принятия управленческих решений, называемые в условиях рынка налоговым менеджментом. Налоговое управление, как часть системы управления рыночной экономикой, является относительно новой областью знаний России, сформировавшейся в конце XX - начале XXI в. В частности, налоговый менеджмент появился в экономической среде, т. е. на практике. Попытки обобщить и развить эту категорию имели место гораздо позже.

Выводы. В статье представлена авторская концепция бухгалтерского и налогового управленческого анализа в торговой организации, в которой отражен ряд аспектов концепции: системное представление информационных ресурсов, средств и источников информации, форм и методов передачи различных данных. Это будет являться основой для интеграции информационной базы, которая соответствует потребностям и запросам налогового администрирования.

Ключевые слова: налоговый менеджмент, концептуальные основы налогового менеджмента, налоговая система, налоги.

\section{Введение}

В Российской Федерации сформировались основные этапы развития категории налогового менеджмента коммерческих организаций (как указано в работе Р. Б. Магеррамова [12].

1. Зарождение налогового менеджмента как способа управления налоговыми обязательствами организации (1990-1999). На дан-

() Костюкова Е. И., Германова В. С., Фролов А. В., 2020 Вестник ВГУ. Серия: Экономика и управление. 2020. № 2. С. 66-74. ном этапе осуществилось первоначальное формирование налогового и гражданского законодательства. За этим последовало желание организаций найти способы уклонения от налогов. Налоговые схемы были незаконными. В сочетании с низкой квалификацией работников они допускали просчеты, которые приводили к тяжелым последствиям подобного снижения налогового бремени. Понятие 
«налоговый менеджмент» на тот момент не существовало, однако было положено начало управлению налоговыми доходами, расходами и обязательствами.

2. Становление налогового менеджмента (2000-2003). На данном этапе налоговый менеджмент стал восприниматься организациями как инструмент законной минимизации налоговых платежей. В начале XXI в. российская налоговая система начала активно развиваться. Экономия на налогах приобрела настолько важное значение, что от нее зависела даже ценовая конкурентоспособность продукции. Государство начало контролировать уменьшение налоговых обязательств путем ограничения налогового планирования. После этого налоговые органы становились свидетельством налогового правонарушения [4; 7-10]. Тогда же появилась первая объективная характеристика категории налогового менеджмента.

3. Развитие налогового менеджмента как налогового планирования (2004-2005). На данном этапе государство приняло налоговое планирование как разумную деловую цель. Появилось понятие оптимизации налогообложения.

4. Установление пределов налогового планирования посредством разграничения налогового менеджмента и налоговой выгоды (2006-2009). Высший арбитражный суд сформулировал понятие налоговой выгоды, благодаря которому значительно увеличилось количество добросовестных налогоплательщиков. Важно, что данный этап объединил в себе идеи и принципы налогового менеджмента. Это позволило сформировать концепцию налогового менеджмента и отметить его управленческий характер как системы управления налоговыми потоками.

5. Налоговый менеджмент как компромисс между интересами государства и организаций (с 2010 г. по настоящее время). Корректировка судебных решений в пользу налогоплательщиков стала связующим звеном между интересами организаций и государства. Налоговое управление эволюционировало от инструмента снижения налогов к оптимальной стратегии корпоративного управления, что согласуется с правовой базой и применением существующего экономического мышления. Именно поэтому категория налогового менеджмента на уровне коммерческой органи- зации может считаться сложившейся. Для современного налогового менеджмента характерны следующие признаки: относительная обособленность от финансового управления; принятие налоговых управленческих решений; укрепление финансов; рационализация хозяйственной деятельности; регулярное увеличение стоимости бизнеса.

\section{Материалы и методы исследования}

Налоговый менеджмент является составной частью всей налоговой политики. Он представляет собой систему принципов и методов в области разработки и реализации управленческих решений, выбора налоговой системы, расчета налоговых платежей, а также постоянного контроля за их осуществлением. Задачами налогового администрирования является анализ экономических отношений общественных организаций и учреждений, возникающих в случае положительного финансового результата.

Исследование опирается на результаты изучения действующих нормативно-правовых актов в области налоговой политики и налогового менеджмента, а также научных трудов авторов, работающих над данной проблемой. Следующие методы научного исследования использовались нами при работе над статьей: моделирование, сравнение, приемы систематизации, обобщения теоретических и практических аспектов в исследуемой области.

\section{Обсуждение результатов}

Как мы видим, налоговый менеджмент развивался совместно с российской налоговой системой и согласно потребностям коммерческих организаций по вопросу воздействия на налоговые показатели с целью их оптимизации.

В классическом варианте концептуальная модель налогового менеджмента коммерческого предприятия подразумевает наличие семи блоков (рис. 1).

Данные финансового и налогового учетов являются основными источниками информации о размере налоговых обязательств. Кроме того, информация об их размере также учитывается в рамках управленческого и стратегического налогового учета. Это говорит о том, что так или иначе все виды учета формируют отчетность, прямо или косвенно содержащую информацию о налоговых обязательствах. 


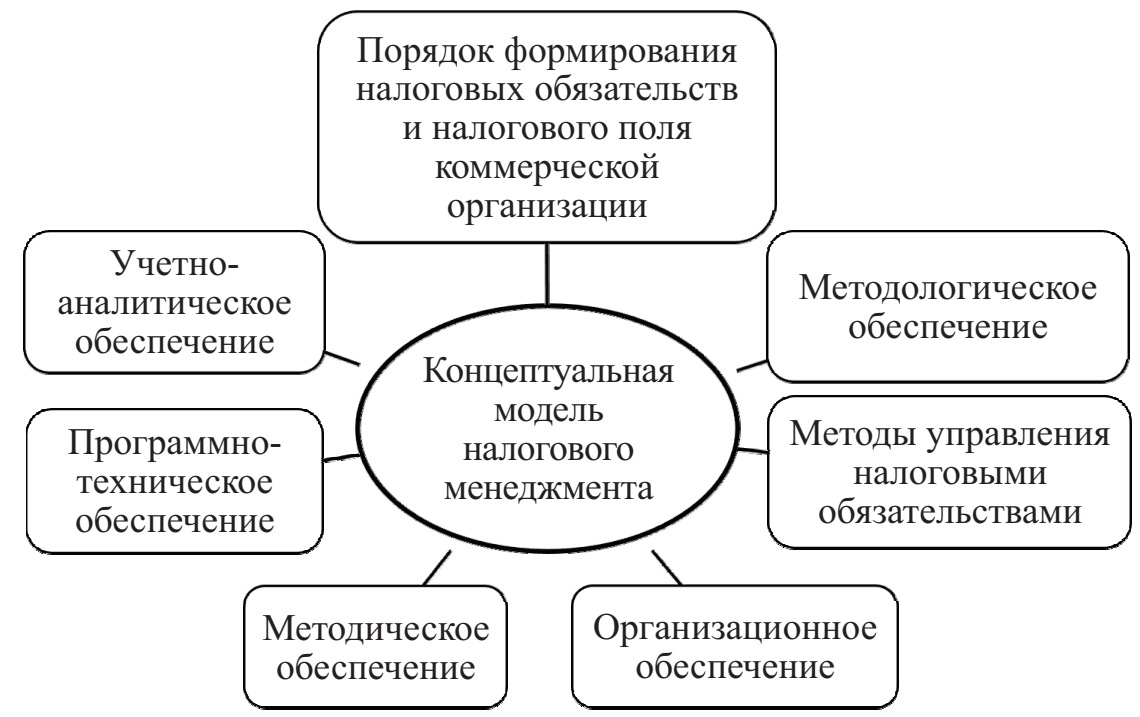

Puc. 1. Концептуальная модель налогового менеджмента

Эффективное управление налоговыми обязательствами непосредственно связано со стратегическим налоговым учетом. Его правильное внедрение способно привести к изменениям в области концептуальных основ ведения учета.

Само понятие учетно-аналитической системы на данном этапе проработанности проблемы в широком смысле состоит в объединении учетных и аналитических процедур воедино, что способствует получению рекомендаций в области эффективности принимаемых налоговых управленческих решений и рациональному управлению налоговыми обязательствами.
Данный информационный подход разделяют многие ученые (рис. 2).

Изучив концептуальные основы налогового менеджмента, можно сделать выводы и дать определения, представленные в табл. 1.

Налоги должны не только выполнять налоговые функции, но и стимулировать деятельность населения. Это методически правильная постановка налогового менеджмента как механизма достижения целей национальной экономики [11; 13-14].

Учитывая различные подходы к пониманию сущности налогового менеджмента,

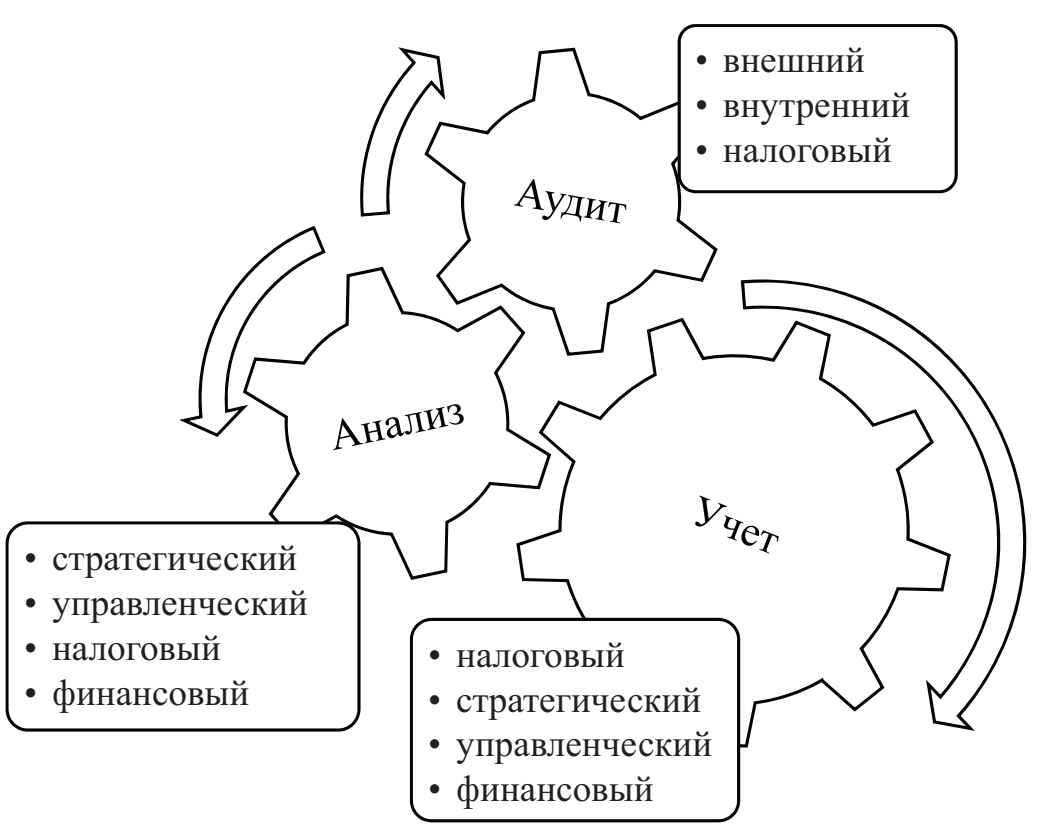

Puc. 2. Модель симбиоза элементов учетно-аналитической системы 
Развитие концептуальных основ налогового менеджмента

Т а бл и ц а 1

Сущность налогового менеджмента

\begin{tabular}{|l|l|}
\hline \multicolumn{1}{|c|}{ Понятие } & \multicolumn{1}{|c|}{ Содержание понятия } \\
\hline Налоговый менеджмент & $\begin{array}{l}\text { Процесс управления налоговой системой в целях исполнения политики } \\
\text { в сфере налогообложения }\end{array}$ \\
\hline $\begin{array}{l}\text { Макроэкономическая цель } \\
\text { налогового менеджмента }\end{array}$ & $\begin{array}{l}\text { Пополнение доходной части бюджета и осуществление влияния налогов } \\
\text { на развитие предпринимательства }\end{array}$ \\
\hline
\end{tabular}

можно сформулировать наиболее общую концепцию, объединяющую взгляды всех ученых. Отношения системы налогового менеджмента при развитии организации, управления, а также движения денежных потоков налоговых субъектов бюджетными субъектами-налогоплательщиками являются той экономической средой, в рамках которой они реализуют свои производственные возможности $[6 ; 15]$. В данном определении налоговый режим рассматривается как научно-практический процесс, направленный на обеспечение функционирования предусмотренного законом налогового механизма.

Многие работы были посвящены вопросам налогового администрирования, но они до сих пор не в полной мере отражают его принципы и содержание. Отсутствие фундаментальных исследований, конечно же, негативно сказывается на практике.

Обобщив приведенные рассуждения, можно сделать вывод, что налоговый менеджмент организует взаимодействия внутренних элементов налоговой системы. Он служит своего рода механизмом, адаптирующимся к управленческой подсистеме и характеристикам внешней среды. Являясь связующим звеном между налогоплательщиком и государством, он обеспечивает пополнение бюджета национального хозяйства.

Изучая мнение ученых [1-2; 16-19], можно сделать вывод, что налоговые административные меры получили надлежащее распределение. Однако учет и анализ вопросов и проблем еще не получили достаточного внимания.

В связи с этим можно выделить ряд проблем.

1. Система нормативного регулирования бухгалтерского и налогового учетов не обеспечивает целостности, поэтому функционирование налогового менеджмента реализуется не в полной мере: существует необходимость ведения двух видов учета (бухгалтерского и налогового), работа значительно ус- ложняется, а информация, формируемая в рамках финансового и налогового учетов, не позволяет получать данные в том объеме, который необходим для анализа всевозможных налоговых последствий [20].

2. Отсутствует комплексный подход к методологии учетно-аналитического обеспечения налогового менеджмента.

3. Недостаточно разработана методологическая и методическая базы подходов к формированию информации.

4. Целью учетно-аналитического обеспечения налогового менеджмента является создание комфортных условий функционирования управленческого учета в области регулирования налоговых потоков, а также информационное моделирование процесса управления налоговыми обязательствами предприятия и повышение его потенциала. Зачастую данная цель попросту не реализуется.

Данные недоработки свидетельствуют о необходимости проведения дальнейших исследований в рассматриваемой области. Кроме того, требуется разработка концепции учетно-аналитического обеспечения налогового менеджмента коммерческой организации $[3 ; 5]$.

Если оценивать вклад ученых в решение исследуемого вопроса, следует всё же отметить, что в данный момент вовсе не существует понятия учетно-аналитического обеспечения налогового менеджмента.

Имеющиеся точки зрения являются общими. Они не отражают истинной сущности процесса налогового менеджмента - целый ряд аспектов учётно-аналитического обеспечения налогового менеджмента остается неохваченным. Это говорит о необходимости дальнейшего развития и совершенствования представлений по данному вопросу.

Исходя из вышеизложенных точек зрения, можно сформулировать несколько наиболее распространенных понятий учетно-аналитического обеспечения налогового менеджмен- 
та. Учетно-аналитическое обеспечение налогового менеджмента в коммерческой организации представляет собой упорядоченную, самостоятельную, адекватную целям управления совокупность:

- в которой с помощью обратной связи используются информационные ресурсы;

- включающую современную систему бухгалтерского учета, экономического анализа и внутреннего контроля, необходимую для снятия всех вопросов пользователей;

- использующую современные разработки и технологии для методического обеспечения.

\section{Заключение}

Концепция системы учета и анализа в самом широком смысле заключается в совмещении бухгалтерских и аналитических процедур, что способствует получению рекомендаций по эффективности решений налогового управления и рациональному управлению налоговой задолженностью.

Налоговый менеджмент является неотъемлемой частью любой налоговой политики. Это система принципов и методов разработки и реализации управленческих решений, выбора налоговой системы, расчета налоговых платежей и постоянного контроля за их выполнением. Задачей налогового органа является анализ экономических отношений государственных организаций и учреждений в случае положительного финансового результата.

Администрация организует взаимодействие внутренних элементов налоговой системы. Она действует как своеобразный механизм, приспосабливающийся к управлению подсистемой и характеристикам внешней среды. Являясь связующим звеном между налогоплательщиком и государством, администрация обеспечивает пополнение бюджета народного хозяйства.

Налоги должны не только выполнять налоговые функции, но и стимулировать деятельность населения. Это методически правильное объяснение налогового управления как механизма достижения целей народного хозяйства.

Принимая во внимание различные подходы к пониманию сущности налогового администрирования, мы можем сформулировать наиболее общую концепцию, объединяющую взгляды всех ученых. При развитии органи- зации, управления и денежного потока налоговых единиц бюджетными единицами-налогоплательщиками являются те экономические условия, в которых они реализуют свои производственные мощности. В этом определении налоговый режим рассматривается как научно-практический процесс, направленный на обеспечение функционирования предусмотренного законом налогового механизма. Эффективность персонала компании остается одной из ключевых проблем налогового менеджмента.

Система нормативного регулирования бухгалтерского и налогового учетов не обеспечивает целостности, поэтому функционирование налогового управления не реализовано в полной мере: поскольку необходимо поддерживать оба вида бухгалтерского учета (бухгалтерский учет и налогообложение), работа намного сложнее, а информация, генерируемая в рамках финансово-налогового учета, не позволяет получить данные в той мере, в какой это необходимо для анализа различных налоговых последствий.

Целью бухгалтерско-аналитической поддержки налогового управления является создание комфортных условий для функционирования административного учета в сфере регулирования налоговых потоков.

Мы можем сформулировать некоторые из наиболее распространенных концепций бухгалтерского учета и аналитической поддержки налогового управления: учет и аналитическая поддержка налогового управления в коммерческой организации - это упорядоченный, независимый и разумный набор целей управления.

Мы сформулировали концепцию бухгалтерского и налогового управленческих анализов в торговой организации. В ней отражен ряд аспектов концепции: системное представление информационных ресурсов, средств и источников информации, форм и методов передачи различных данных. Все это создает основу для интеграции информационной базы, которая соответствует потребностям и запросам налогового администрирования.

Предлагаемый подход направлен на расширение научных представлений о налогово-бюджетном управлении, основанном на бухгалтерском учете, с целью обоснования рекомендации по совершенствованию налогового управ- 
ления, которая базируется на разработке методик бухгалтерского учета и анализа, применяемых в системе бухгалтерского учета и анализа хозяйственной организации в частности.

\section{Источник финансирования}

Источником финансирования процесса исследования являются средства, полученные в рамках выполнения государственного контракта № 155/19 от 6 августа 2019 г. с Министерством сельского хозяйства Ставропольского края.

\section{Библиографический список}

1. Adhami S. Why do businesses go crypto? An empirical analysis of initial coin offerings / S. Adhami, G. Giudici, S. Martinazzi // Journal of Economics and Business. - 2018. - Vol. 100. - P. 64-75.

2. Mamycheva D. I. Instrumentation organizational and economic support of labor motivation of employees / D. I. Mamycheva e.a. // International Review of Management and Marketing. - 2016. - T. 6, no. 1. P. 142-147.

3. Milovanova E. Strategic planning features of regional development in increased exogenous volatility conditions / E. Milovanova, V. Molodyh, I. Morozova, E. Ostapenko // Journal of Social Sciences Research. 2018. - № 4 (12). - P. 515-520.

4. Бабурян Л. М. Сравнительный анализ организации налогового консультирования в России и зарубежных странах / Л. М. Бабурян // Вестник ИПБ (Вестник профессиональных бухгалтеров). - 2016. № 3. - C. 3438.

5. Байдаков А. Н. Влияние личностного фактора на управление экономическими системами / А. Н. Байдаков, Д. В. Запорожец, Д. С. Кенина // Актуальные проблемы управления аграрным бизнесом : монография. - Ставрополь : АГРУС Ставропольского гос. аграрного ун-та, 2013.

6. Башкатов В. В. Налогообложение добычи и использования криптовалют в Российской Федерации / В. В. Башкатов, Е. С. Сюткина // Вестник ИПБ (Вестник профессиональных бухгалтеров). 2018. - № 4. - С. 36-40.

7. Волкова Ю. Б. Консолидированная финансовая отчетность : учебное пособие / Ю. Б. Волкова, Т. А. Лаврухина, Н. Н. Решетова, Н. Г. Сапожникова, М. В. Ткачева. - Воронеж : Изд-во Воронеж. гос. ун-та, 2017.

8. Емельянов А. С. Участие иностранного капитала в финансировании российских организаций / А. С. Емельянов, А. А. Горохов, О. Н. Углицких, Ю. Е. Клишина // Инновационная экономика : перспективы развития и совершенствования. - 2016. № 1 (11). - C. 67-71.

\section{Благодарности}

Выражаем благодарность за предоставленную возможность реализовать на практике теоретические разработки в области налогового менеджмента врио ректора Ставропольского государственного аграрного университета, профессору Ивану Вячеславовичу Атанову.

\section{Конфликт интересов}

Авторы декларируют отсутствие явных и потенциальных конфликтов интересов, связанных с публикацией настоящей статьи.

9. Ендовицкий Д. А. Экономический анализ слияний/поглощений компаний / Д. А. Ендовицкий, В. Е. Соболева. - Москва : КноРус, 2008.

10. Звягинцева О. С. Совершенствование процесса принятия управленческих решений в организации / О. С. Звягинцева, Д. С. Кенина, Л. И. Черникова, А. П. Исаенко // Российский экономический интернет-журнал. - 2018. - № 2. - С. 30.

11. Зотиков Н. 3. Направления совершенствования налогового администрирования / Н. 3. Зотиков // Вестник ИПБ (Вестник профессиональных бухгалтеров). - 2017. № 5. - С. 33-42.

12. Магеррамов Р. Б. Роль современных информационных технологий в совершенствовании налогового менеджмента / Р. Б. Магеррамов // Роль финансов и учёта в развитии финансовой системы. - 2018. - № 1. - С. 152-159.

13. Паскачев А. Б. Налоги и налогообложение / А. Б. Паскачев. - М. : Высшее образование, 2010. $231 \mathrm{c}$.

14. Поршнев А. Г. Налоговый менеджмент / А. Г. Поршнев. - М. : ИНФРА-М, 2009. - 623 с.

15. Склярова Ю. М. Инвестиции / Ю. М. Склярова, И. Ю. Скляров, Л. А. Латышева. - Ростов-н/Д. : Феникс, 2015.

16. Ткач E. В. Налоговый менеджмент как неотъемлемая функция корпоративного управления процессом налогообложения на современном предприятии / Е. В. Ткач // Инновационное развитие. - 2018. - № 3 (20). - С. 65-68.

17. Ткачева М. В. Анализ финансового состояния корпораций для обеспечения их экономической безопасности / М. В. Ткачева, К. А. Черкасова // Апрельские научные чтения имени профессора Л. Т. Гиляровской : материалы VII Междунар. науч.-практ. конф. : в 2 ч. / под ред. Д. А. Ендовицкого, Л. С. Коробейниковой. - 2018. - С. 293-297.

18. Хоружий Л. И. Партнерский бенчмаркинг как инструмент обеспечения экономической безопасности в системе межфирменного сотрудничества агроформирований / Л. И. Хоружий, Ю. Н. Катков, А. А. Романова // Вестник ИПБ 
(Вестник профессиональных бухгалтеров). - 2018. № 4. - С. 41-48.

19. Хоружий Л. И. Теория и практика бухгалтерского учета в условиях современного информационного общества / Л. И. Хоружий, И. В. Харчева, А. И. Павлычев // Вестник ИПБ (Вестник профессиональных бухгалтеров). - 2017. № 2. - С. 28-35.
20. Цвиринько И. А. Кризисный менеджмент основа финансового оздоровления предприятия / И. А. Цвиринько, В. И. Бережной, И. В. Таранова // Вестник Института дружбы народов Кавказа. Теория экономики и управления народным хозяйством. - 2011. - № 4-2 (20). - С. 13-17.
Костюкова Елена Ивановна, доктор экономических наук, профессор кафедры бухгалтерского управленческого учета, Ставропольский государственный аграрный университет, Ставрополь, Российская Федерация

E-mail: elena-kostyukova@yandex.ru

ORCID ID: 0000-0003-0626-7462

Германова Виктория Самвеловна, кандидат экономических наук, доцент кафедры бухгалтерского финансового учета, Ставропольский государственный аграрный университет, Ставрополь, Российская Федерация

E-mail: v.s.germanova@yandex.ru

ORCID ID: 0000-0002-6794-4802

Фролов Александр Витальевич, кандидат экономических наук, доцент кафедры бухгалтерского финансового учета, Ставропольский государственный аграрный университет, Ставрополь, Российская Федерация

E-mail: froloffman@mail.ru

ORCID ID: 0000-0003-3535-2957

Поступила в редакцию 17.03.2020

Подписана в печать 15.04.2020 


\title{
Development of the conceptual foundations of tax management
}

\author{
E. I. Kostyukova ${ }^{1}$, V. S. Germanova ${ }^{2}$, A. V. Frolov ${ }^{3 凶}$ \\ 1,2,3 Stavropolsky state agrarian University, per. Zootechnicheskiy, 12, 355017, Stavropol, Russian Federation
}

Cite as: Kostyukova, E. I., Germanova, V. S., Frolov, A. V. (2020). Development of the conceptual foundations of tax management. Proceedings of Voronezh State University. Series: Economics and Management. 2, 66-74. (In Russ., abstract in Eng.) DOI: 10.17308/econ.2020.2/2902

Importance. The goal of the strategy for sustainable development of the Russian Federation is to ensure stable indicators of economic growth, as well as to solve socio-economic, industrial, technological and environmental problems on the basis of optimal use of innovative and scientific and technical potential, updating equipment and technologies, and expanding sales markets. At the same time, the effectiveness of the innovation process itself will largely depend on the readiness of economic entities to introduce and use modern knowledge-intensive technologies, which may manifest themselves in tax policy.

Objectives. Justification and clarification of the facts that tax management is an integral part of the entire tax policy and is a system of principles and methods in the development and implementation of management decisions, the choice of the tax system, the calculation of tax payments, as well as constant monitoring of their implementation.

Methods. The instrumental and methodological apparatus of the research is based on the use of General scientific and special methods, including abstract-logical, monographic, computational and constructive, methods of risk analysis, economic and mathematical modeling, graphic, methods of multidimensional statistical analysis, content analysis.

Results. At all times, taxes have been the most important tool of state regulation, implementing the main tasks of the state. Taxation creates tax relations that need to be properly regulated through the application of tax legislation. This interaction encourages economic entities to manage their tax payments. Therefore, they begin to apply in their activities a wide variety of methods of making managerial decisions, called tax management in the market. Tax management is a management model of tax management implemented by taxpayers in a macro-economic environment that exploits their production capacity. Tax administration, as part of the market economy management system, is a relatively new area of knowledge in Russia, which was formed in the late XX-early XXI centuries. In particular, tax management appeared in the economic environment, i.e. in practice. Attempts to generalize and develop this category took place much later.

Conclusions and Relevance. The article presents the author's concept of accounting and tax management analysis in a trade organization, which reflects a number of aspects of the concept: system representation of information resources, means and sources of information, forms and methods of transmitting various data. This will be the basis for integrating the information base that meets the needs and requests of tax administration.

Key words: tax management, conceptual foundations of tax management, tax system, taxes.

\section{Source of Financing}

The source of funding for the research process is the funds received under the state contract № 155/19 dated 06.08.2019 with the Ministry of agriculture of the Stavropol territory.

\section{Acknowledgement}

We are grateful for the opportunity to put into practice the theoretical developments in the field of tax management of the Acting rector of Stavropol state agrarian University, Professor Ivan Atanov.

\section{Conflict of Interest}

The authors declare that there are no obvious or potential conflicts of interest associated with the publication of this article. 


\section{References}

1. Adhami, S., Giudici, S. \& Martinazzi S. (2018) Why do businesses go crypto? An empirical analysis of initial coin offerings. Journal of Economics and Business, 100, 64-75.

2. Mamycheva, D. I., Melnichuk, A. V., Taranova, I. V., Chernykh, A. I., Gadzhieva, E. Y. \& Ratiev, V. V. (2016) Instrumentation organizational and economic support of labor motivation of employees. International Review of Management and Marketing. 6, 1, 142-147.

3. Milovanova, E., Molodyh, V., Morozova, I. \& Ostapenko, E. (2018) Strategic planning features of regional development in increased exogenous volatility conditions. Journal of Social Sciences Research, 4 (12), 515-520.

4. Baburyan, L. M. (2016) Comparative analysis of the organization of tax consulting in Russia and foreign countries. Vestnik IPB [Bulletin of professional accountants], 3, 34-38. (In Russ.)

5. Baidakov, A. N., Zaporozhets, D. V. \& Kenina, D. S. (2013) Influence of the personal factor on the management of economic systems. In Baidakov, A. N. (ed.) Actual problems of agricultural business management. Stavropol. AGRUS of Stavropol St. Agrarian Univ. (In Russ.)

6. Bashkatov, V. V. (2018) Taxation of production and use of cryptocurrencies in the Russian Federation. Vestnik IPB [Bulletin of professional accountants]. 4, 36-40. (In Russ.)

7. Volkova, Yu. B., Lavrukhina, T. A., Reshetova, N. N., Sapozhnikova, N. G. \& Tkacheva, M. V. (2017) Consolidated financial statements. Voronezh. Voronezh St. Univ. Publ. (In Russ.)

8. Emelyanov, A. S., Gorokhov, A. A., Uglitsky, O.N. \& Klishina, Yu. E. (2016) Participation of foreign capital in financing of Russian organizations. Innovative economy: prospects for development and improvement, 1(11), 67-71. (In Russ.)

9. Endovitsky, D. A., Soboleva, V.E. (2008) Financial Analysis of Mergers and Acquisitions. Moscow, KnoRus Publ. (In Russ.)

10. Zvyagintseva, O. S., Kenina, D. S., Chernikova, L. I. \& Isaenko, A. P. (2018) Improving the process of making managerial decisions in the organization. Russian economic online journal, 2, 30. (In Russ.)

11.Zotikov, N.Z. (2017) Directions of improvement of tax administration. Vestnik IPB [Bulletin of professional accountants], 5, 33-42. (In Russ.)

12. Magerramov, R. B. (2018) The role of modern information technologies in improving tax management. The Role of Finance and accounting in the development of the financial system, 1, 152-159. (In Russ.)

13. Paskachev, A. B. (2010) Taxes and taxation. Moscow. Higher education publ. (In Russ.)

14. Porshnev, A. G. (2009) Tax management. Moscow, INFRA-M. (In Russ.)

15. Sklyarova, Yu. M., Sklyarov, I. Yu. \& Latysheva, L. A. (2015) Investment. Rostov-on-Don. Feniks Publ. (In Russ.)

16. Tkach, E. V. (2018) Tax management as an integral function of corporate management of the taxation process in a modern enterprise. Innovative development. 3 (20), 65-68. (In Russ.)

17. Tkacheva, M. V. \& Cherkasova, K. A. (2018) [Analysis of the financial state of corporations to ensure their economic security]. Proceedings of April scientific readings named after Professor L. T. Gilyarovskaya. Voronezh, pp. 293-297. (In Russ.)

18. Horuzhiy, L. I., Katkov, Yu. N. \& Romanova, A. A. (2018) Partner benchmarking as a tool to ensure economic security in the system of inter-firm cooperation of agricultural formations. Vestnik IPB [Bulletin of professional accountants], 4, 41-48. (In Russ.)

19. Horuzhiy, L. I., Kharcheva, I. V. \& Pavlychev, A. I. (2017) Theory and practice of accounting in the conditions of modern information society. Vestnik IPB [Bulletin of professional accountants], 2, 28-35. (In Russ.)

20. Tsvirinko, I. A., Berezhnoy, V. I. \& Taranova, I.V. (2011) Crisis management - the basis of financial recovery of the enterprise. Bulletin of the Institute of friendship of the peoples of the Caucasus Theory of Economics and national economy management, 4-2 (20), 13-17. (In Russ.)
Elena I. Kostyukova, Dr. Sci. (Econ.), Prof., Department of Management Accounting, Stavropol State Agrarian University, Stavropol, Russian Federation

E-mail: elena-kostyukova@yandex.ru

ORCID ID: 0000-0003-0626-7462

Viktoriya S. Germanova, Cand. Sci. (Econ.), Assoc. Prof., Department of Financial Accounting, Stavropol State Agrarian University, Stavropol, Russian Federation

E-mail: v.s.germanova@yandex.ru

ORCID ID: 0000-0002-6794-4802
Alexandr V. Frolov, Cand. Sci. (Econ.), Assoc. Prof., Department of Financial Accounting, Stavropol State Agrarian University, Stavropol, Russian Federation

E-mail: froloffman@mail.ru

ORCID ID: 0000-0003-3535-2957

Received 17.03.2020

Accepted 15.04.2020 